Proceedings of the 16th Czech and Slovak Conference on Magnetism, Košice, Slovakia, June 13-17, 2016

\title{
X-Ray Diffraction Study of $\mathrm{CeT}_{2} \mathrm{Al}_{10}(\mathrm{~T}=\mathrm{Ru}, \mathrm{Os})$ at Low Temperatures and under Pressures
}

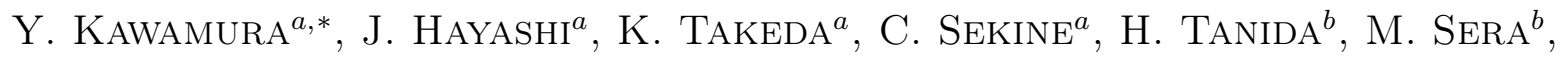 \\ S. NAKANO ${ }^{c}$, T. TOMITA ${ }^{d}$, H. TAKAHASHI ${ }^{e}$ AND T. NishIOKA ${ }^{f}$ \\ ${ }^{a}$ Muroran Institute of Technology, Muroran, Hokkaido 050-8585, Japan \\ ${ }^{b}$ Hiroshima University, Higashi-Hiroshima, Hiroshima 739-8530, Japan \\ ${ }^{c}$ National Institute for Materials Science, Tsukuba, Ibaraki 305-0044, Japan \\ ${ }^{d}$ ISSP, University of Tokyo, Kashiwa, Chiba 277-8581, Japan \\ ${ }^{e}$ Nihon University, Sakurajosui, Setagaya, Tokyo 156-8550, Japan \\ ${ }^{f}$ Kochi University, Kochi, Kochi 780-8520, Japan
}

\begin{abstract}
We have carried out a powder X-ray diffraction investigation on antiferromagnetic Kondo semiconductors $\mathrm{CeRu}_{2} \mathrm{Al}_{10}$ and $\mathrm{CeOs}_{2} \mathrm{Al}_{10}$ at low temperatures and under high pressures as well as the structural investigation on single crystal of these compounds. The results of powder X-ray studies of $\mathrm{CeRu}_{2} \mathrm{Al}_{10}$ and $\mathrm{CeOs}_{2} \mathrm{Al}_{10}$ indicate that these compounds do not have structural transition at its antiferromagnetic ordering temperature. The results of single crystal structural refinement indicate that the $b$-axis of this crystal structure is insensitive not only to pressure but also to temperature and that the effect of cooling to $\mathrm{Ce}-\mathrm{Ce}$ distance for $\mathrm{CeRu}_{2} \mathrm{Al}_{10}$ is the same as that for $\mathrm{CeOs}_{2} \mathrm{Al}_{10}$.
\end{abstract}

DOI: 10.12693/APhysPolA.131.988

PACS/topics: $61.50 . \mathrm{Ks}$

\section{Introduction}

$\mathrm{CeT}_{2} \mathrm{Al}_{10}(\mathrm{~T}=\mathrm{Ru}, \mathrm{Os})$ crystallizes in orthorhombic structure (space group Cmcm No. 63) [1]. These compounds have been reported to exhibit antiferromagnetic $(\mathrm{AFM})$ ordering at ordering temperatures $\left(T_{N}\right)$ of $\mathrm{CeRu}_{2} \mathrm{Al}_{10}$ and $\mathrm{CeOs}_{2} \mathrm{Al}_{10}$ are 27.3 and $28.7 \mathrm{~K}$, respectively $[2,3]$. These compounds are also reported as a Kondo semiconductor, the gap of which is due to the strong $c-f$ hybridization. Optical conductivity studies have confirmed the $c-f$ hybridization gap in $\mathrm{CeRu}_{2} \mathrm{Al}_{10}$ and in $\mathrm{CeOs}_{2} \mathrm{Al}_{10}$ are 35 and $45 \mathrm{meV}$, respectively $[4,5]$.

These compounds have been extensively studied because of the coexistence of AFM ordering and $c-f$ hybridization gap. Neutron scattering have confirmed the existence of antiferromagnetic ordering in both $\mathrm{CeRu}_{2} \mathrm{Al}_{10}$ and $\mathrm{CeOs}_{2} \mathrm{Al}_{10}$ [6-8]. These $T_{N}$ values are about 100 times higher than that would be expected from the de Gennes law [3]. The electronic instability, which accompanies structural instability, is one possible drive force for the high $T_{N}$ of $\mathrm{CeRu}_{2} \mathrm{Al}_{10}$ and $\mathrm{CeOs}_{2} \mathrm{Al}_{10}$.

The $T_{N}$ of $\mathrm{CeRu}_{2} \mathrm{Al}_{10}$ and $\mathrm{CeOs}_{2} \mathrm{Al}_{10}$ suddenly disappear at a critical pressure $\left(P_{C}\right) \approx 4 \mathrm{GPa}$ and $2.5 \mathrm{GPa}$, respectively $[3,9]$. This sudden disappearance, like a first-order transition, implies the possibility of a pressureinduced structural transition near $P_{C}$. This study focuses on $T_{N}$ and on $P_{C}$ at room temperatures and the effect of cooling to the structure.

\footnotetext{
* corresponding author; e-mail:

y_kawamura@mmm.muroran-it.ac.jp
}

In this paper, we report the synchrotron X-ray studies of $\mathrm{CeRu}_{2} \mathrm{Al}_{10}$ and $\mathrm{CeOs}_{2} \mathrm{Al}_{10}$ around $T_{N}$ and as well as those under pressure. We also report the analysis of single crystal structure at $110 \mathrm{~K}$ and $300 \mathrm{~K}$.

\section{Experimental details}

$\mathrm{CeRu}_{2} \mathrm{Al}_{10}$ and $\mathrm{CeOs}_{2} \mathrm{Al}_{10}$ were grown by $\mathrm{Al}$ self flux method. For the analysis of single crystal structure, we use a piece of single crystal of $\mathrm{CeRu}_{2} \mathrm{Al}_{10}$ with $50 \mu \mathrm{m} \times 40 \mu \mathrm{m} \times 20 \mu \mathrm{m}$ and that of $\mathrm{CeOs}_{2} \mathrm{Al}_{10}$ with $70 \mu \mathrm{m} \times 50 \mu \mathrm{m} \times 20 \mu \mathrm{m}$. The measurements of single crystal structure were performed on a Rigaku Saturn724 diffractometer using multi-layer mirror monochromated Mo $K_{\alpha}$ radiation.

For the experiment of synchrotron powder X-ray diffraction, the single crystals were grinded into a fine powder. The uniform grain was obtained by using sedimentation method. The pressure was applied by diamond anvil pressure cell (DAC). The measurement down to $10 \mathrm{~K}$ was cooled with GM refrigerator. The sample was exposed by the beam with a size of $\Phi 100 \mu \mathrm{m}$ in diameter and with a wave length $\lambda \approx 0.62 \AA$. Imaging plate was used as a detector. In order to eliminate remaining spots of the Debye ring, a stage of the DAC was oscillated during synchrotron X-ray exposure. The mixture of methanol and ethanol with 4:1 ratio was used as pressure transmission. The pressure was evaluated by ruby fluorescence method.

\section{Results and discussions 3.1. Powder X-ray diffraction}

Figure 1 shows the $\mathrm{X}$-ray diffraction pattern of $\mathrm{CeRu}_{2} \mathrm{Al}_{10}$ and $\mathrm{CeOs}_{2} \mathrm{Al}_{10}$ around $P_{C}$ at room temperature. The diffraction pattern of $\mathrm{CeRu}_{2} \mathrm{Al}_{10}$ at $4.2 \mathrm{GPa}$ is 
not changed from that at $3.1 \mathrm{GPa}$ except a slight change of peaks position due to the contraction of lattice parameters. Because the $P_{C}$ of $\mathrm{CeRu}_{2} \mathrm{Al}_{10}$ is from $3 \mathrm{GPa}$ to $4 \mathrm{GPa}$, this result indicates the lack of structural change around $P_{C}$ at room temperature. In addition, the intensity ratio of the peaks does not change from 3.1 GPa to 4.2 $\mathrm{GPa}$, which implies the lack of structural deformation around $P_{C}$ at room temperature.

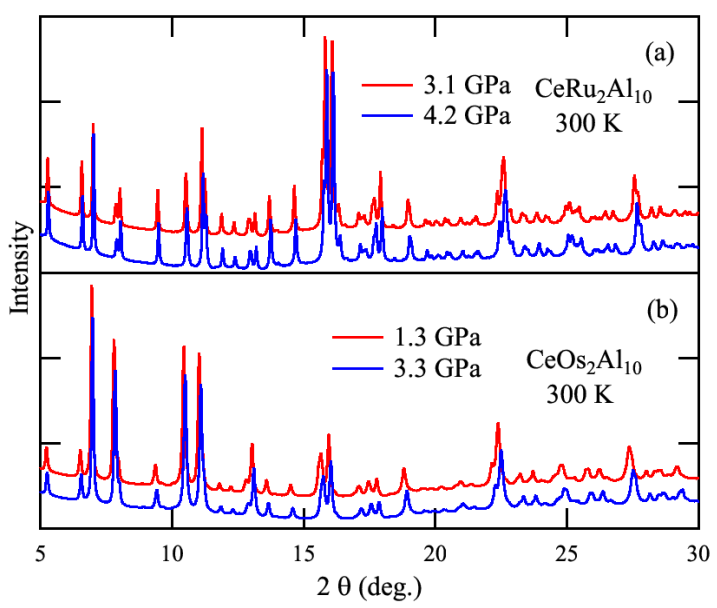

Fig. 1. X-ray diffraction pattern of (a) $\mathrm{CeRu}_{2} \mathrm{Al}_{10}$ and

(b) $\mathrm{CeOs}_{2} \mathrm{Al}_{10}$ at the pressure below $P_{C}$ (top) and above $P_{C}$ (bottom).

Similar results can be seen in the X-ray diffraction patterns of $\mathrm{CeOs}_{2} \mathrm{Al}_{10}$. The diffraction pattern of $\mathrm{CeOs}_{2} \mathrm{Al}_{10}$ at $3.3 \mathrm{GPa}$ is not changed from that at $1.3 \mathrm{GPa}$ except a slight change of peaks position. In addition, the intensity ratio of the peaks does not change from $1.3 \mathrm{GPa}$ to $3.3 \mathrm{GPa}$. Because the $P_{C} \approx 2.5 \mathrm{GPa}$ for $\mathrm{CeOs}_{2} \mathrm{Al}_{10}$, these results imply the lack of structural change and deformation around $P_{C}$ at room temperature.

Although the angles of the peaks of $\mathrm{CeRu}_{2} \mathrm{Al}_{10}$ are not so different from that of $\mathrm{CeOs}_{2} \mathrm{Al}_{10}$ due to the similar lattice constant, the relative peak intensity of each peaks is considerable different as can be seen in Fig. 1. This difference is due to the difference of the atomic position.

Figure 2 shows the X-ray diffraction pattern around $T_{N}$ below $P_{C}$. Neither peak disappearance nor peak splitting are observed. Furthermore, the intensity of the peak does not change a lot at different temperatures. We note that the background of $\mathrm{CeRu}_{2} \mathrm{Al}_{10}$ and $\mathrm{CeOs}_{2} \mathrm{Al}_{10}$ is different, which is due to the change of Mylar sheet at the window of GM refrigerator.

We evaluated bulk modulus by the Birch equation of state [10]:

$$
\begin{aligned}
P & =3 / 2 B_{0}\left[\left(i / i_{0}\right)^{-7}-\left(i / i_{0}\right)^{-5}\right] \\
& \times\left\{1+3 / 4\left(B_{0}^{\prime}-4\right)\left[\left(i / i_{0}\right)^{-2}-1\right]\right\},
\end{aligned}
$$

where $B_{0}$ is the bulk modulus, $B_{0}^{\prime}$ is its first pressure derivative, $P$ is the pressure, $i(i=a, b, c)$ denotes the lattice parameters, $i_{0}\left(i_{0}=a_{0}, b_{0}, c_{0}\right)$ denotes the lattice parameters at ambient pressure. $B_{0}$ of $a, b, c$ for

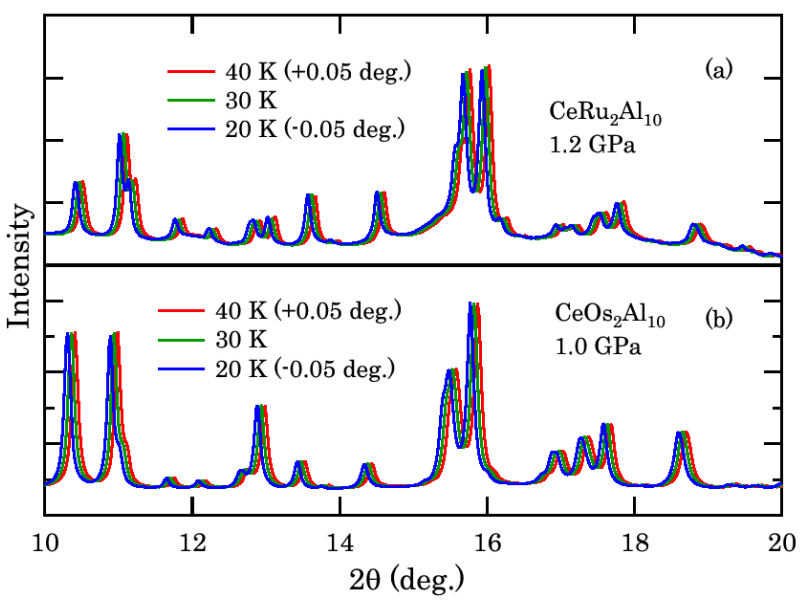

Fig. 2. X-ray diffraction pattern of (a) $\mathrm{CeRu}_{2} \mathrm{Al}_{10}$ and (b) $\mathrm{CeOs}_{2} \mathrm{Al}_{10}$ at $20 \mathrm{~K}$ (left), $30 \mathrm{~K}$ (middle), and $40 \mathrm{~K}$ (right). The peaks are shifted for clarity as indicated in the parenthesis.

$\mathrm{CeRu}_{2} \mathrm{Al}_{10}$ is derived to $101,128,97 \mathrm{GPa}$, respectively. In addition, $B_{0}$ of $a, b$, and $c$ for $\mathrm{CeOs}_{2} \mathrm{Al}_{10}$ is derived to 106, 144, and $108 \mathrm{GPa}$, respectively.

The $B_{0}$ of $V$ assuming cubic approximation are among these values; $105 \mathrm{GPa}$ for $\mathrm{CeRu}_{2} \mathrm{Al}_{10}$ and $120 \mathrm{GPa}$ for $\mathrm{CeOs}_{2} \mathrm{Al}_{10}$ [11]. The large value of $b$ indicates that lattice parameter is insensitive to pressure. The difference of $B_{0}$ for $b$ parameter for $\mathrm{CeOs}_{2} \mathrm{Al}_{10}$ from the other axis is more distinctive than that of $\mathrm{CeRu}_{2} \mathrm{Al}_{10}$.

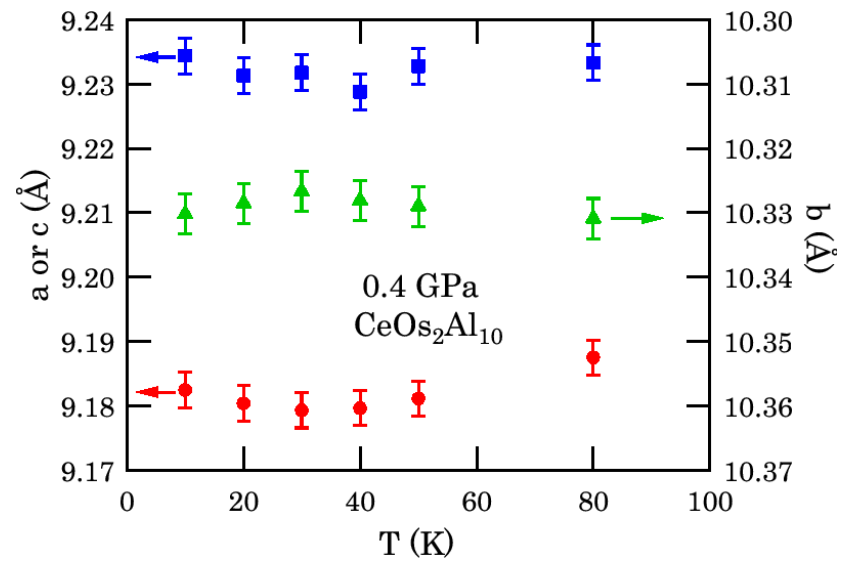

Fig. 3. Lattice parameter $a$ (circle, left axis), $b$ (triangle, right axis), and $c$ (square, left axis) at low temperatures of $\mathrm{CeOs}_{2} \mathrm{Al}_{10}$ below $P_{C}$.

Figure 3 shows the lattice parameters of $\mathrm{CeOs}_{2} \mathrm{Al}_{10}$ at low temperatures below $P_{C}$. There is no distinct difference around $T_{N}$ out of this experimental error attributed to the change of pressure and to the shrink of GM refrigerator by cooling. These results do not contradict to the previous lattice parameters obtained from neutron diffraction with a small anomaly in the case of $b$ parameter at $30 \mathrm{~K}$, because the error bar of neutron diffraction is smaller [12]. 


\subsection{Single crystal analysis}

In order to evaluate the effect of cooling on lattice parameters for $\mathrm{CeOs}_{2} \mathrm{Al}_{10}$ and for $\mathrm{CeRu}_{2} \mathrm{Al}_{10}$, we performed single crystal $\mathrm{X}$-ray structure refinement. The refinement parameters of $\mathrm{CeRu}_{2} \mathrm{Al}_{10}$ with $R=0.028$, $w R=0.062$, and $S=1.19$ are compatible to the previous report with $R=0.043, w R=0.123$, and $S=1.10$ [13].

Table I shows the lattice parameter of $\mathrm{CeRu}_{2} \mathrm{Al}_{10}$ and $\mathrm{CeOs}_{2} \mathrm{Al}_{10}$ at $300 \mathrm{~K}$ and at $110 \mathrm{~K}$. The $a$ and $c$ parameters of $\mathrm{CeOs}_{2} \mathrm{Al}_{10}$ are longer than those of $\mathrm{CeRu}_{2} \mathrm{Al}_{10}$, while the $b$ parameter of $\mathrm{CeOs}_{2} \mathrm{Al}_{10}$ is almost the same as that of $\mathrm{CeRu}_{2} \mathrm{Al}_{10}$. This small $b$ parameter for $\mathrm{CeOs}_{2} \mathrm{Al}_{10}$ induces the large difference of $B_{0}$ of $b$ from that of $a$ and $c$. The differences of lattice parameters $a$, $b$, and $c$ at $110 \mathrm{~K}$ from those at $300 \mathrm{~K}$ for $\mathrm{CeRu}_{2} \mathrm{Al}_{10}$ are $0.23 \%, 0.12 \%, 0.21 \%$, respectively. Those for $\mathrm{CeOs}_{2} \mathrm{Al}_{10}$ are $0.18 \%, 0.09 \%, 0.21 \%$, respectively.

\section{TABLE I}

Lattice parameters and $\mathrm{Ce}-\mathrm{Ce}$ distance of $\mathrm{CeRu}_{2} \mathrm{Al}_{10}$ and that of $\mathrm{CeOs}_{2} \mathrm{Al}_{10}$. Estimated standard deviations are given in parentheses.

\begin{tabular}{c|c|c|c|c}
\hline \hline \multirow{2}{*}{} & \multicolumn{2}{|c|}{$\mathrm{CeRu}_{2} \mathrm{Al}_{10}$} & \multicolumn{2}{c}{$\mathrm{CeOs}_{2} \mathrm{Al}_{10}$} \\
\cline { 2 - 5 } & $300 \mathrm{~K}$ & $110 \mathrm{~K}$ & $300 \mathrm{~K}$ & $110 \mathrm{~K}$ \\
\hline$a[\AA]$ & $9.120(2)$ & $9.099(3)$ & $9.139(2)$ & $9.123(3)$ \\
$b[\AA]$ & $10.268(2)$ & $10.256(4)$ & $10.267(3)$ & $10.258(3)$ \\
$c[\AA]$ & $9.181(2)$ & $9.162(3)$ & $9.187(2)$ & $9.168(3)$ \\
$\mathrm{Ce}-\mathrm{Ce}[\AA]$ & 5.247 & 5.237 & 5.271 & 5.261
\end{tabular}

Overall, the lattice parameters of $\mathrm{CeRu}_{2} \mathrm{Al}_{10}$ are more sensitive to cooling than those of $\mathrm{CeOs}_{2} \mathrm{Al}_{10}$. This is the same tendency as the $B_{0} \mathrm{~s}$ of $\mathrm{CeRu}_{2} \mathrm{Al}_{10}$ are smaller than those of $\mathrm{CeOs}_{2} \mathrm{Al}_{10}$, where $B_{0}$ means the hardness against pressure. The lattice parameters of $b$ for $\mathrm{CeRu}_{2} \mathrm{Al}_{10}$ and $\mathrm{CeOs}_{2} \mathrm{Al}_{10}$ are insensitive to cooling. This tendency is consistent with the results that the lattice parameter of $b$ is insensitive to pressure compared to that of $a$ or $c$.

Next, we discuss the relation between lattice parameters and physical properties. When $\mathrm{CeRu}_{2} \mathrm{Al}_{10}$ is compared to $\mathrm{CeFe}_{2} \mathrm{Al}_{10}$, the lattice parameter has an anisotropic contraction. We proposed that the shrinkage of lattice parameters $a$ and $c$ is related to the enhancement of the anisotropic $c-f$ hybridization [11]. When $\mathrm{CeRu}_{2} \mathrm{Al}_{10}$ is compared to $\mathrm{CeOs}_{2} \mathrm{Al}_{10}$, the effect of $c^{-}$ $f$ hybridization cannot be related to chemical pressure. Although the $c-f$ hybridization of $\mathrm{CeRu}_{2} \mathrm{Al}_{10}$ is smaller than that of $\mathrm{CeOs}_{2} \mathrm{Al}_{10}$, the volume and the $\mathrm{Ce}-\mathrm{Ce}$ distance of $\mathrm{CeRu}_{2} \mathrm{Al}_{10}$ are smaller than those of $\mathrm{CeOs}_{2} \mathrm{Al}_{10}$.

On the other hand, the $\mathrm{Ce}-\mathrm{Ce}$ distance decreases by $0.19 \%$ from $300 \mathrm{~K}$ to $110 \mathrm{~K}$ for both compounds, which indicates the effect of cooling is the same in these compounds. This study reveals that the comparison of temperature dependence of physical properties on $\mathrm{CeRu}_{2} \mathrm{Al}_{10}$ and that on $\mathrm{CeOs}_{2} \mathrm{Al}_{10}$ is fruitful because $\mathrm{Ce}-\mathrm{Ce}$ distance is essential factor for discussing $c-f$ hybridization and magnetic ordering at $T_{N}$.

\section{Conclusions}

We have investigated structure of $\mathrm{CeRu}_{2} \mathrm{Al}_{10}$ and $\mathrm{CeOs}_{2} \mathrm{Al}_{10}$ at low temperature and at high pressures. Powder X-ray diffraction does not show any hint of structural change or modification at $T_{N}$ or $P_{C}$ at room temperature. The structural analysis of the single crystal indicates that the $b$-axis of this crystal structure is insensitive not only to pressure but also to cooling and that the effect of cooling of $\mathrm{Ce}-\mathrm{Ce}$ distance for $\mathrm{CeRu}_{2} \mathrm{Al}_{10}$ is the same as that for $\mathrm{CeOs}_{2} \mathrm{Al}_{10}$.

\section{Acknowledgments}

The synchrotron radiation experiments were carried out at BL-18C in KEK with the approval of the Photon Factory Program Advisory Committee (proposal Nos. 2013G501, 2015G512). This work was partially supported by JSPS KAKENHI (grant Nos. 15K17687 and 23340092).

\section{References}

[1] V.M.T. Thiede, T. Ebel, W. Jeitschoko, J. Mater. Chem. 8, 125 (1998).

[2] A.M. Strydom, Physica B 404, 2981 (2009).

[3] T. Nishioka, Y. Kawamura, T. Takesaka, R. Kobayashi, H. Kato, M. Matsumura, K. Kodama, K. Matsubayashi, Y. Uwatoko, J. Phys. Soc. Jpn. 78, 123705 (2009).

[4] S. Kimura, T. Iizuka, H. Miyazaki, T. Hajiri, M. Matsunami, T. Mori, A. Irizawa, Y. Muro, J. Kajino, T. Takabatake, Phys. Rev. B 84, 165125 (2011).

[5] S. Kimura, T. Iizuka, H. Miyazaki, A. Irizawa, Y. Muro, T. Takabatake, Phys. Rev. Lett. 106, 056404 (2011).

[6] J. Robert, J.M. Mignot, G. Andre, T. Nishioka, R. Kobayashi, M. Matsumura, H. Tanida, D. Tanaka, M. Sera, Phys. Rev. B 82, 100404 (2010).

[7] D.D. Khalyavin, A.D. Hillier, D.T. Adroja, A.M. Strydom, P. Manuel, L.C. Chapon, P. Peratheepan, K. Knight, P. Deen, C. Ritter, Y. Muro, T. Takabatake, Phys. Rev. B 82, 100405 (2010).

[8] D.T. Adroja, A.D. Hillier, P.P. Deen, A.M. Strydom, Y. Muro, J. Kajino, W.A. Kockelmann, T. Takabatake, V.K. Anand, J.R. Stewart, J. Taylor, Phys. Rev. B 82, 104405 (2010).

[9] K. Umeo, T. Ohsuka, Y. Muro, J. Kajino, T. Takabatake, J. Phys. Soc. Jpn. 80, 064709 (2011).

[10] F. Birch, Phys. Rev. 71, 809 (1947).

[11] Y. Kawamura, J. Hayashi, K. Takeda, C. Sekine, H. Tanida, M. Sera, T. Nishioka, J. Phys. Soc. Jpn. 85, 044601 (2016).

[12] D.T. Adroja, A.D. Hillier, Y. Muro, T. Takabatake, A.M. Strydom, A. Bhattacharyya, A.D. Aladin, J.W. Taylor, Phys. Scr. 88, 068505 (2013).

[13] A.I. Tursina, S.N. Nesterenko, E.V. Murashova, I.V. Chernyshev, H. Noël, Y.D. Seropegin, Acta Crystallogr. E 61, i12 (2005). 